\title{
Research and Application of Dynamic Risk Analysis Model for Zhejiang Hazardous Chemical Production Enterprises
}

\author{
Sanqiang Chen, Jianmiao Zhu, Fengmei Ye \\ Zhejiang Academy of Safety Science and Technology, Hangzhou 310012,China

\section{浙江省危险化学品生产企业动态风险分析模型 研究与应用 \\ 陈三强、朱建菻、叶峰梅} \\ 浙江省安全生产科学研究院, 杭州 310012 , 中国
}

\begin{abstract}
:
Zhejiang is a major province for the production and consumptionof hazardous chemicals. Chemical industry safety accidents in Zhejiang province since 12th Five-Year Plan were analyzed and a dynamic risk assessment model for chemical enterprises was proposed.Some risk factors, such as the attributes of dangerous chemicals, reaction processes, major hazard sourcesand the level of automation were obtained based on information of hazardous chemical enterprises. This article developed consequence static risk indicator of chemicalenterprises. Then, dynamic factors such as special operation, trial production, stop and start of production line, inspection and maintenance, contractor's work, weather conditions and so on, were integrated to probe into the essence of accident in chemical industry. Possibility dynamic risk indicator of chemicalenterprises was given. Furthermore, based onthestatic and dynamicindicator, dynamic risk assessment model of chemical enterprises could be established through risk matrix scheme. Finally, the designed dynamic risk model has been applied to 1156hazardous chemicals productionenterprises in Zhejiang province. The result shows the changing of hazardous chemicals safety risk managementfrom macroscopic to
\end{abstract}

microcosmic, qualitative to quantitative and uncertainty tocertainty.

Keywords:hazardouschemical; security management; dynamic risk; risk model

\section{摘要}

浙江是危化品大省, 本文基于 “十二五” 以来 浙江省化工行业安全事故的统计分析, 对危险化学 品生产企业风险分级管控模型进行了研究。首先通 过危险化学品企业的基本信息收集, 获取企业客观 存在的一些风险因素, 如危化品属性、反应工艺、 重大危险源以及自动化水平等, 构建企业后果性静 态风险指标。再进一步分析化工企业事故的内在原 因, 整合特种作业、试生产、开停车、检维修、承 包商作业、天气情况等动态因素, 获得可能性动态 风险指标。在此基础上, 采用风险矩阵法创建了静 态和动态风险相关联的化工企业动态安全风险研 判模型, 并对浙江省内 1156 家危化品生产企业进 行了风险分级应用, 初步实现危险化学品安全风险 管控从宏观向微观、定性向定量、不确定向确定转 变。

关键词: 危化品; 安全管理; 动态风险; 风险模型

1、背景

随着人们的生活质量的提高和社会生产力的 发展, 民众对危化品的依赖程度越来越高, 而危化 品固有的危险特性令现代社会充斥着巨大的风险 
[1]。2013 年 11 月 22 日, 青岛输油管道泄露爆炸 事故, 造成 62 人死亡、 136 人受伤, 直接经济损 失 7.5 亿元。2 2015 年 8 月 12 日, 天津港危险化学 品仓库火灾懪炸事故, 造成 173 人死亡、 798 人受 伤, 直接经济达 68.66 亿元。诸如此类的危化品事 故不但造成了巨大的人员伤亡和巨额的财产损失, 且社会影响范围广, 引起了普通民众对于危化品的 恐慌, 成为影响社会和谐和稳定的重要因素, 因而 危化品安全管理是当前一项迫切需要关注和解决 的问题。为此, 2016 年国务院下发了《关于印发 危险化学品安全综合治理方案的通知》(国办发 (2016) 88 号), 对我国的危化品安全管理提出了 明确的工作目标和治理要求。

浙江是危化品大省, 化工行业产值超过 1 万亿 元。如何加强和保障化工行业的安全生产更是是全 社会共同的心声和努力的方向。2017 年初, 浙江 省发布了《危险化学品安全综合治理实施方案》以 及《危险化学品安全风险预防大数据平台建设工作 方案》, 提出了建设浙江省危化品企业安全风险预 防大数据平台的要求。而危化品生产企业的风险分 级模型建设和应用是大数据平台中的重要环节, 通
过模型建立和应用, 将实现政府建设管理、企业申 报信息、数据共建共享、部门分工监管的综合管理, 形成员工、企业、政府、社会多方参与、良性互动 的风险动态管控数字生态系统, 实现风险管控从宏 观到微观、从定性到定量、从不确定性到确定性的 “蝶变”。

\section{2、浙江省化工企业事故情况及事故原因分析}

本文通过对浙江省“十二五” 以来的化工行业 的安全生产事故[2]进行统计分析, 探索化工事故频 发的原因及其发生规律, 将大量的、已知的化工事 故统计资料和事故调查报告作为基础数据, 、采用 数理统计的原理和方法进行分析 ${ }^{[3]}$, 获得了浙江省 危化品生产企业动态风险分级研判模型。

\section{1 浙江省“十二五”以来化工企业事故总体情况}

根据浙江省事故直报系统数据分析, “十二五” 以来浙江省化工企业共发生安全生产事故 93 起, 死亡 115 人, 其中: 较大事故 8 起, 一般事故 85 起, 未发生重特大事故。

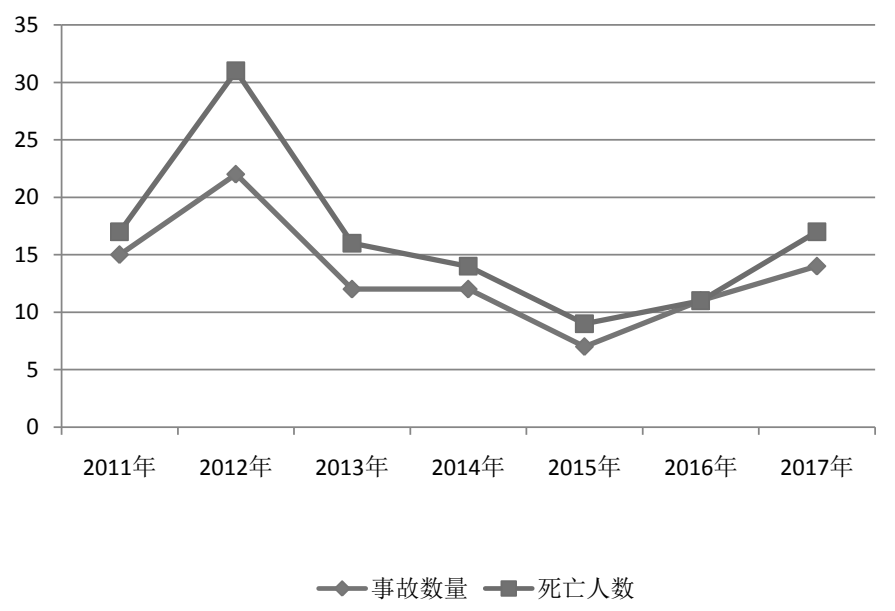

图 1 浙江省“十二五”以来化工领域事故

\section{2 化工企业事故类型统计分析}

按照《企业职工伤亡事故分类》(GB6441-86) 分析, “十二五”以来, 浙江省化工企业发生的死亡人
数较多的类型是爆炸、中毒窒息和高处坠落, 具体 化工事故类型分布情况如图 2 所示。 


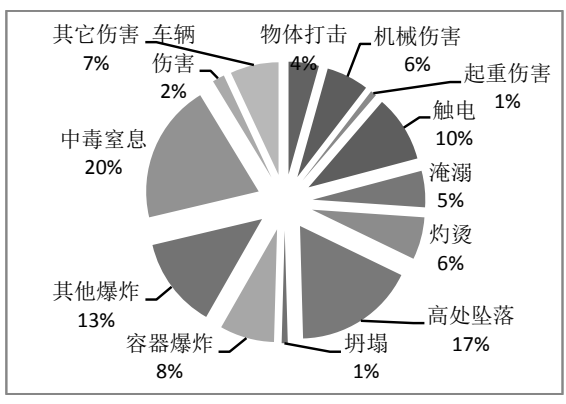

图 2 化工事故类型分布

\section{3 化工企业事故特征}

从事故数据来看, 化工事故的特征基本上是由 原料特征、加工工艺、生产规模和管理状态所决定 的。主要特征有:

(1)火灾爆炸中毒事故多且后果严重。根据事故 统计资料表明, 化工火灾爆炸事故居第一位; 中毒 室息事故占第二位; 高处芏落占第三位。

(2)非正常生产或检维修时易发生事故。一般化 工企业目前自动化程度已经明显提升, 因此在正常 生产的情况下, 发生事故的比例较低, 当出现检维 修、设备安装等非正常生产状态时, 事故容易高发, 经事故统计资料表明, 在企业非正常生产时发生的 事故占 $40 \%$ 以上。

(3)化工设备失效导致事故。由于设备在运行中 长期受物质的腐蚀、机械振动、压力波动和高低温 冲击等影响, 导致设备失效从而发生事故。

(4)管理不善且违章违纪现象较为严重。企业的 安全生产, 关键在于企业各级领导是否自觉遵章守 纪, 重视安全。大量事实证明: 不少管理人员不能 正确处理安全与生产的关系, 最终酿成事故。此外, 工人素质良莠不齐也另外一个主要原因。常见的问 题有: 缺乏应有的化工知识和安全常识, 违章违纪 现象严重, 且缺乏处置应急事件的能力。

\section{4 化工企业事故发生原因分析}

在现有的事故直报系统中, 部分地区对事故划 分类型并不明确和固化, 因此有必要对浙江省安全 生产事故发生调查报告进行深度解读, 通过进一步 的分析, 发现事故统计中出现的淹溺事故大部分发 生于化工企业清理罐体和池体, 而从事故发生场景 来看, 这段时间内的淹溺事故和中毒窒息事故也可 划为有限空间事故。同时, 2017 年化工企业发生的 2 起较大事故中, 由于企业自私变更工艺及违法进行 中扩试引发冲料事故, 在事故分类中归类于其他伤 害。根据统计结果可归纳出近“十二五”以来化工事故 发生的原因主要有以下几种:

(1)工人违规操作, 未经批准, 擅自进行动火作
业、受限空间作业等;

(2)工人操作失误;

(3)设备损坏导致原料泄漏, 工人缺乏处置应急 事件的能力;

(4) 新产品新工艺不过关就进行生产, 如中扩试、 试生产等;
(5)工厂布局不合理, 生产装置安全水平低等;
(6)未佩戴防护装置等;
(7)恶劣天气或外部环境。

\section{3 危化品生产企业安全风险分析与模型建立 3.1 危险化学品企业中的风险因素}

危险化学品企业具有危险性大、防范难度高、 事故损失大、社会影响范围广的特点。一方面在危 险化学品企业中多发生爆炸、中毒、火灾等事故并 且其后果较严重, 另一方面在危险化学品企业中管 理水平、企业规模参差不齐, 工作人员的素质相差 较大, 员工“三违”现象是事故发生主要原因 [4]。此外, 危险化学品企业的各个环节都有可能发生事故, 比 如生产、经营、运输、存储、使用、废弃等等, 给 监管带来很大难度 ${ }^{[5]}$ 。从资料调查和监管要求分析, 危险化学品企业中的风险因素有以下几点:

(1)从业单位基础状况——危险化学品企业在安 全生产过程中受影响的基础以及基本条件的因素。 包括生产类型, 生产规模, 运行状态, 人员素质, 自动化程度, 事故应急救援等。

(2) 安全管理状况一一反映着企业安全生产管理 方面保障能力的因素。内部变量分别是管理组织机 构、安全管理制度、专兼职安全生产管理人员、安 全培训教育。

(3)季节因素一一反映着季节对企业风险概率影 响的因素。包含的变量主要是高温、雷雨等季节因 素的影响。

(4) 安全业绩与历史事故——反映着企业安全生 产方面的成效以及行为惯例的因素。

\section{2 危险化学品企业动态安全风险模型构建}

针对危险化学品生产企业安全技术状况、季节 条件、安全管理状况、安全业绩与历史事故及企业 基本情况 ${ }^{[6]}$ 明确界定危化品生产企业的风险因素, 将 风险因素分为静态风险指标和动态风险指标, 通过 这些因素的指标构建, 从而建立企业动态风险模型。

\subsection{1 基于风险的静态指标设计}

2018 年 5 月, 应急管理部印发了《危险化学品 生产储存企业安全风险评估诊断分级指南 (试行)》 (应急 (2018) 19 号), 明确提出了危险化学品生 产储存企业的安全风险评估诊断分级标准。为确保 模型的政策符合性, 将该分级指南作为模型的静态 风险指标, 详见下表 1 。 
表 1 危险化学品生产储存企业安全风险评估诊断分级指南

\begin{tabular}{|c|c|c|}
\hline 类别 & 项目 (分值) & 评估内容 \\
\hline \multirow{9}{*}{$\begin{array}{l}\text { 1. 固有危险 } \\
\text { 性 }\end{array}$} & \multirow{4}{*}{$\begin{array}{l}\text { 重大危险源 } \\
\text { (10 分) }\end{array}$} & 存在一级危险化学品重大危险源的, 扣 10 分; \\
\hline & & 存在二级危险化学品重大危险源的, 扣 8 分; \\
\hline & & 存在三级危险化学品重大危险源的, 扣 6 分; \\
\hline & & 存在四级危险化学品重大危险源的, 扣 4 分。 \\
\hline & \multirow{3}{*}{$\begin{array}{l}\text { 物质危险性 } \\
\text { (5 分) }\end{array}$} & 生产、储存爆炸品的（实验室化学试剂除外), 每一种扣 2 分; \\
\hline & & $\begin{array}{l}\text { 生产、储存 (含管道输送) 氯气、光气等吸入性剧毒化学品的（实验室化学试剂除 } \\
\text { 外), 每一种扣 } 2 \text { 分; }\end{array}$ \\
\hline & & 生产、储存其他重点监管危险化学品的 (实验室化学试剂除外), 每一种扣 0.1 分。 \\
\hline & $\begin{array}{l}\text { 危险化工工艺种 } \\
\text { 类 } \\
\text { (10 分) }\end{array}$ & 涉及 18 种危险化工工艺的, 每一种扣 2 分。 \\
\hline & $\begin{array}{l}\text { 火灾爆炸危险性 } \\
\text { (5 分) }\end{array}$ & $\begin{array}{l}\text { 涉及甲类/乙类火灾危险性类别厂房、库房或者罐区的, 每涉及一处扣 } 1 / 0.5 \text { 分; } \\
\text { 涉及甲类、乙类火灾危险性罐区、气柜与加热炉等与产生明火的设施、装置比邻布 } \\
\text { 置的, 扣 } 5 \text { 分。 }\end{array}$ \\
\hline \multirow[b]{2}{*}{ 2. 周边环境 } & \multirow[b]{2}{*}{$\begin{array}{l}\text { 周边环境 } \\
\text { (10 分) }\end{array}$} & 企业在化工园区（化工集中区）外的，扣 3 分; \\
\hline & & $\begin{array}{l}\text { 企业外部安全防护距离不符合《危险化学品生产、储存装置个人可接受风险标准和 } \\
\text { 社会可接受风(险标准 (试行)》的, 扣 } 10 \text { 分。 }\end{array}$ \\
\hline \multirow{3}{*}{$\begin{array}{l}\text { 3. 设计与评 } \\
\text { 估 }\end{array}$} & \multirow{3}{*}{$\begin{array}{l}\text { 设计与评估（10 } \\
\text { 分） }\end{array}$} & $\begin{array}{l}\text { 国内首次使用的化工工艺未经过省级人民政府有关部门组织安全可靠性论证的, 扣 } \\
5 \text { 分; }\end{array}$ \\
\hline & & 精细化工企业未按规范性文件要求开展反应安全风险评估的，扣 10 分; \\
\hline & & 企业危险化学品生产储存装置均由甲级资质设计单位进行全面设计的, 加 2 分。 \\
\hline \multirow{3}{*}{ 4.设备 } & \multirow{3}{*}{ 设备（5 分） } & 使用淘汰落后安全技术工艺、设备目录列出的工艺及设备的，每一项扣 2 分; \\
\hline & & 特种设备没有办理使用登记证书的, 或者未按要求定期检验的, 扣 2 分; \\
\hline & & 化工生产装置未按国家标准要求设置双电源或者双回路供电的，扣 5 分。 \\
\hline \multirow{6}{*}{$\begin{array}{l}\text { 5. 自控与安 } \\
\text { 全设施 }\end{array}$} & \multirow{6}{*}{$\begin{array}{l}\text { 自控与安全设施 } \\
\text { (10 分) }\end{array}$} & $\begin{array}{l}\text { 涉及重点监管危险化工工艺的装置未按要求实现自动化控制, 系统未实现紧急停车 } \\
\text { 功能, 装备的自动化控制系统、紧急停车系统未投入使用的, 扣 } 10 \text { 分; } \\
\text { 涉及毒性气体、液化气体、剧毒液体的一级、二级重大危险源的危险化学品罐区未 } \\
\text { 配备独立的安全仪表系统的, 扣 } 10 \text { 分; }\end{array}$ \\
\hline & & 构成一级、二级重大危险源的危险化学品罐区未实现紧急切断功能的, 扣 5 分; \\
\hline & & $\begin{array}{l}\text { 危险化学品重大危险源未设置压力、液位、温度远传监控和超限位报警装置的, 每 } \\
\text { 涉及一项扣 } 1 \text { 分; }\end{array}$ \\
\hline & & $\begin{array}{l}\text { 涉及可燃和有毒有害气体泄漏的场所未按国家标准设置检测声光报警设施的, 每一 } \\
\text { 处扣 } 1 \text { 分; }\end{array}$ \\
\hline & & 防爆区域未按国家标准安装使用防爆电气设备的, 每一处扣 1 分; \\
\hline & & $\begin{array}{l}\text { 甲类、乙类火灾危险性生产装置内设有办公室、操作室、固定操作岗位或休息室的, } \\
\text { 每涉及一处扣 } 5 \text { 分。 }\end{array}$ \\
\hline \multirow{5}{*}{ 6.人员资质 } & \multirow{5}{*}{$\begin{array}{l}\text { 人员资质 } \\
\text { (15 分) }\end{array}$} & 企业主要负责人和安全生产管理人员未依法经考核合格的，每一人次扣 5 分; \\
\hline & & $\begin{array}{l}\text { 企业专职安全生产管理人员不具备国民教育化工化学类 (或安全工程) 中等职业教 } \\
\text { 育以上学历或者化工化学类中级以上专业技术职称的, 每一人次扣 } 5 \text { 分; }\end{array}$ \\
\hline & & $\begin{array}{l}\text { 涉及“两重点一重大”装置的生产、设备及工艺专业管理人员不具有相应专业大专以 } \\
\text { 上学历的, 每一人次扣 } 5 \text { 分; }\end{array}$ \\
\hline & & 企业未按有关要求配备注册安全工程师的, 扣 3 分; \\
\hline & & $\begin{array}{l}\text { 企业主要负责人、分管安全生产工作负责人、安全管理部门主要负责人为化学化工 } \\
\text { 类专业毕业的, 每一人次加 } 2 \text { 分。 }\end{array}$ \\
\hline \multirow{3}{*}{$\begin{array}{l}\text { 7. 安全管理 } \\
\text { 制度 }\end{array}$} & \multirow{3}{*}{$\begin{array}{l}\text { 管理制度 } \\
\text { (10 分) }\end{array}$} & $\begin{array}{l}\text { 未制定操作规程和工艺控制指标或者制定的操作规程和工艺控制指标不完善的, 扣 } \\
5 \text { 分; }\end{array}$ \\
\hline & & $\begin{array}{l}\text { 动火、进入受限空间等特殊作业管理制度不符合国家标准或未有效执行的, 扣 } 10 \\
\text { 分; }\end{array}$ \\
\hline & & 未建立与岗位相匹配的全员安全生产责任制的，每涉及一个岗位扣 2 分。 \\
\hline 8.应急管理 & 应急配备 & 企业自设专职消防应急队伍的, 加 3 分。 \\
\hline \multirow{7}{*}{$\begin{array}{l}\text { 9. 安全管理 } \\
\text { 绩效 }\end{array}$} & \multirow{3}{*}{$\begin{array}{l}\text { 安全生产标准化 } \\
\text { 达标 }\end{array}$} & 安全生产标准化为一级的, 加 15 分; \\
\hline & & 安全生产标准化为二级的, 加 5 分; \\
\hline & & 安全生产标准化为三级的, 加 2 分。 \\
\hline & \multirow{4}{*}{$\begin{array}{l}\text { 安全事故情况 } \\
\text { (10 分) }\end{array}$} & 三年内发生过 1 起较大安全事故的, 扣 10 分; \\
\hline & & 三年内发生过 1 起安全事故造成 1-2 人死亡的, 扣 8 分; \\
\hline & & $\begin{array}{l}\text { 三年内发生过爆炸、着火、中毒等具有社会影响的安全事故, 但未造成人员伤亡的, } \\
\text { 扣 } 5 \text { 分; }\end{array}$ \\
\hline & & 五年内未发生安全事故的, 加 5 分。 \\
\hline
\end{tabular}


根据分级指南, 存在下述几个情况的企业其风 险级别直接判断为红色, 即最高等级。1、新开发 的危险化学品生产工艺未经小试、中试和工业化试 验直接进行工业化生产的; 2、在役化工装置未经 正规设计且未进行安全设计诊断的; 3、危险化学 品特种作业人员未持有效证件上岗或者未达到高 中以上文化程度的; 4、三年内发生过重大以上安 全事故的, 或者三年内发生 2 起较大安全事故, 或 者近一年内发生 2 起以上亡人一般安全事故的。作 为分级指标, 安全风险从高到低依次对应为红色、 橙色、黄色、蓝色。总分在 90 分以上 (含 90 分) 的为蓝色 (四级); 75 分 (含 75 分) 至 90 分的为 黄色 (三级); 60 分 (含 60 分) 至 75 分的为橙色 (二级); 60 分以下的为红色 (一级)。

\subsection{2 基于风险的动态指标设计}

在浙江省“十二五”以来的事故统计分析中发 现“八大类作业”引发的安全生产事故, 如: 高处坠 落、触电、中毒窒息等在化工行业事故中占比高达 $60 \%$ 以上。这与国家在这方面政策方针、标准规范 的严格要求相一致, 如: 原国家安全生产监督管理 总局第 64 号令《化工 (危险化学品) 企业保障生 产安全十条规定》明确指出: “严禁未经审批进行 动火、进入受限空间、高处、吊装、临时用电、动 土、检维修、盲板抽堵等作业。”[7]2014 年在国家 总局此基础上以国家标准的形式发布了《化学品生 产单位特殊作业安全规范》(GB 30871-2014), 将 化工行业的特殊作业安全规范从行标升级为国标。 因此“八大类”作业应严格纳入危化品生产企业动 态风险评价指标。对作业风险进行严格控制, 也符 合静态风险中的安全管理要求。

在事故分析过程中发现很多事故发生在作业 外包和检维修期间, 如: 2011 年 1 月 24 日, 绍兴 某石化企业火炬塔安装事故、2012 年 11 月 20 日 桐乡市某化工企业安装污水设备工程事故、2017 年 07 月 23 日宁波某化工企业外协单位作业人员潜 水百检查作业事故等。

根据浙江省精细化工的特征, 中 (扩) 试、试 生产和生产线开停车过程也是风险较高状态, 如 2013 年 6 月 7 日杭州某农药企业咪酰胺车间中试 事故、2017 年 6 月 6 日上虞某化工企业违规中扩 试事故等。

同时, 在高温及恶劣天气状态下, 工作人员受 外围环境影响较大, 事故概率也有所提升, 因此天 气环境也是动态风险因素之一。

综上所述, 根据国家法律法规及浙江省事故统 计分析, 选择八大类作业、承包商作业、中（扩） 试、试生产、生产线开停车状态和气象预警为危化 品生产企业风险动态指标。并邀请从事危化品企业 监管的政府工作人员 10 名、危化品企业安全管理 者 5 名, 对危险因素指标值进行打分, 分析结果如 下表 2 所示。
表 2 动态风险因素指标结果

\begin{tabular}{|c|c|c|c|c|}
\hline $\begin{array}{l}\text { 评 价类 } \\
\text { 型 }\end{array}$ & $\begin{array}{l}\text { 指 标 说 } \\
\text { 明 }\end{array}$ & $\begin{array}{l}\text { 分 级 指 } \\
\text { 标 }\end{array}$ & $\begin{array}{l}\text { 打 分 标 } \\
\text { 准 }\end{array}$ & 分值 \\
\hline \multirow{29}{*}{$\begin{array}{l}\text { 动 态 风 } \\
\text { 险 (C2) }\end{array}$} & \multirow{3}{*}{$\begin{array}{l}\text { 动 火作 } \\
\text { 业 }\end{array}$} & $\begin{array}{l}\text { 特 级 动 } \\
\text { 火 }\end{array}$ & \multirow{29}{*}{$\begin{array}{c}\text { 每项指 } \\
\text { 标总分 } 5 \\
\text { 分。分重 } \\
\text { 要、中 } \\
\text { 等、一 } \\
\text { 般、不重 } \\
\text { 要四个 } \\
\text { 等级。 } \\
3.5-5 \text { 为 } \\
\text { 重要, } \\
2.5-3.5 \\
\text { 为中等, } \\
1-2.5 \text { 为 } \\
\text { 一般, } \\
0-1 \text { 为不 } \\
\text { 重要。保 } \\
\text { 留小数 } \\
\text { 点 } 1 \text { 位。 }\end{array}$} & 5 \\
\hline & & $\begin{array}{l}\text { 一 级 动 } \\
\text { 火 }\end{array}$ & & 3 \\
\hline & & 二 级 动 & & 2 \\
\hline & \multirow{2}{*}{$\begin{array}{l}\text { 有 限 空 } \\
\text { 间作业 }\end{array}$} & 有 & & 5 \\
\hline & & 无 & & 0 \\
\hline & \multirow{2}{*}{$\begin{array}{l}\text { 盲 板 抽 } \\
\text { 堵 }\end{array}$} & 有 & & 3 \\
\hline & & 无 & & 0 \\
\hline & \multirow{2}{*}{$\begin{array}{l}\text { 高 处 作 } \\
\text { 业 }\end{array}$} & 有 & & 3 \\
\hline & & 无 & & 0 \\
\hline & \multirow{2}{*}{$\begin{array}{l}\text { 吊 装 作 } \\
\text { 业 }\end{array}$} & 有 & & 3 \\
\hline & & 无 & & 0 \\
\hline & \multirow{2}{*}{$\begin{array}{l}\text { 临 时 用 } \\
\text { 电 }\end{array}$} & 有 & & 3 \\
\hline & & 无 & & 0 \\
\hline & \multirow{2}{*}{$\begin{array}{l}\text { 动 土作 } \\
\text { 业 }\end{array}$} & 有 & & 3 \\
\hline & & 无 & & 0 \\
\hline & \multirow{2}{*}{$\begin{array}{l}\text { 断 路 作 } \\
\text { 业 }\end{array}$} & 有 & & 3 \\
\hline & & 无 & & 0 \\
\hline & \multirow{2}{*}{$\begin{array}{l}\text { 检维 修 } \\
\text { 作业 }\end{array}$} & 有 & & 2.5 \\
\hline & & 无 & & 0 \\
\hline & \multirow{2}{*}{$\begin{array}{l}\text { 承 包 商 } \\
\text { 作业 }\end{array}$} & 有 & & 2 \\
\hline & & 无 & & 0 \\
\hline & \multirow{2}{*}{$\begin{array}{l}\text { 试 生 产 } \\
\text { 期 }\end{array}$} & 有 & & 1.5 \\
\hline & & 无 & & 0 \\
\hline & \multirow{2}{*}{$\begin{array}{l}\text { 开 停 车 } \\
\text { 状态 }\end{array}$} & 有 & & 1.5 \\
\hline & & 无 & & 0 \\
\hline & \multirow{2}{*}{ 中扩试 } & 有 & & 2.5 \\
\hline & & 无 & & 0 \\
\hline & \multirow{2}{*}{$\begin{array}{l}\text { 天 气 预 } \\
\text { 警 }\end{array}$} & 有 & & 1.5 \\
\hline & & 无 & & 0 \\
\hline
\end{tabular}

\subsection{3 基于静态和动态风险的评价模型}

根据危化品生产企业风险因素的分析以及风 险指数法和风险矩阵法的适用范围, 选择风险指数 法和风险矩阵法相结合的模型 [8]对危化品生产企 业进行风险评价。

适用范围: 浙江省范围内所有危险化学品生产 企业的风险评价分级。

数学模型: 风险指数法结合风险矩阵分析法。

量化方法: 综合上述静态指标和动态指标, 为 危化品生产企业设计基于风险的危险因素分级指 标。

根据国家分级指南和浙江省对于化学品生产 企业分级的要求，对静态风险权重进行后果性风险 等级划分进行了修正, 将其小于 60 分的危险企业 进行了二级划分, 将国家的 4 级指标划分为 5 级, 其中 S1 和 S2 均为国家划分要求中的红色等级。具 体划分如下: 


\begin{tabular}{|c|c|c|}
\hline \multicolumn{3}{|c|}{ 表 3 静态风险等级划分 } \\
\hline 序号 & $\begin{array}{l}\text { 危险 性 分 值 } \\
\text { (D1) }\end{array}$ & $\begin{array}{l}\text { 静态风险等级 } \\
\text { (R) }\end{array}$ \\
\hline S1 & $<=40$ & I（高） \\
\hline S2 & $40-60$ & II (较高) \\
\hline S3 & $60-75$ & III（中） \\
\hline S4 & $75-90$ & IV（较低） \\
\hline S5 & $>=90$ & V（低） \\
\hline $\begin{array}{l}\text { 指标与 } \\
\text { 性风| }\end{array}$ & $\begin{array}{l}\text { 动态风险权重分值白 } \\
\text { 与动态风险打分方 } \\
\text { I分, 划分等级如下: }\end{array}$ & $\begin{array}{l}\text { 旧临界值 D2（D2 } \\
\text { 去一致）进行可能 }\end{array}$ \\
\hline & 表 4 动态风险等级戈 & \\
\hline 序号 & $\begin{array}{l}\text { 可 能 性 分 值 } \\
\text { (D2) }\end{array}$ & $\begin{array}{l}\text { 静态风险等级 } \\
\text { (R) }\end{array}$ \\
\hline L1 & $30-50$ & I（高） \\
\hline $\mathrm{L} 2$ & $20-30$ & II（较高） \\
\hline L3 & $10-20$ & III（中） \\
\hline L4 & $5-10$ & IV（较低） \\
\hline L5 & $0-5$ & V（低） \\
\hline
\end{tabular}

根据上述等级划分, 进行风险矩阵构建, 形成 情况如下:

表 5 风险矩阵模型

\begin{tabular}{lllllll}
\hline \multirow{2}{*}{ 风险矩阵 } & \multicolumn{2}{c}{ 可能性风险 } \\
\cline { 2 - 7 } 后 & S1 & L2 & L3 & L4 & L5 \\
\cline { 2 - 6 } 果 & 一级 & 一级 & 二级 & 三级 & 四级 \\
\cline { 2 - 7 } 性 & 一级 & 二级 & 三级 & 三级 & 四级 \\
\cline { 2 - 6 } 风 & 二级 & 二级 & 三级 & 三级 & 四级 \\
\cline { 2 - 7 } & S4 & 二级 & 三级 & 三级 & 四级 & 四级 \\
\cline { 2 - 7 } & S5 & 三级 & 三级 & 四级 & 四级 & 四级 \\
\hline
\end{tabular}

\section{4 动态安全风险分析模型的应用}

本文利用前述风险分析模型, 研发了危险化学 品生产企业风险隐患管控日志系统[9], 尝试开展浙 江省内的危化品生产企业风险研判的探索和应用。 静态指标方面, 目前该日志系统已将浙江省内危化 品生产企业、带储存（仓储）经营企业、使用危化 品的化工企业、加油站、危化品使用单位等基础信 息整理入库, 实现了浙江省大部分危化品企业的固 有风险信息采集 $[10]$ 。其中危化品生产企业和经营带 储存企业的基础信息包括企业基本情况、危化品存 储情况 (含危化品原料、中间体、产品、使用品等 类型的详细信息)、重大危险源情况、重点监管工 艺情况等四类数据。动态指标方面, 该日志系统要 求企业对八大作业等 14 项行为进行实时申报、每 日研判。对事故高发的工作环境，企业也必须及时 申报、每日研判。目前, 浙江省 1156 家危化品生 产企业每天上午 10 点前, 都会将当日动态风险通 过日志系统进行上报, 系统通过静态基础数据与动 态风险数据根据模型进行分级研判, 将研判结果在 企业大屏、政府网站进行风险公告, 实时输出红、 橙、黄、蓝四级风险预警提示信息。真正搭建起员
工、企业、政府、社会多方参与、良性互动的风险 动态管控数字生态系统。详情如图 3 和图 4 所示。
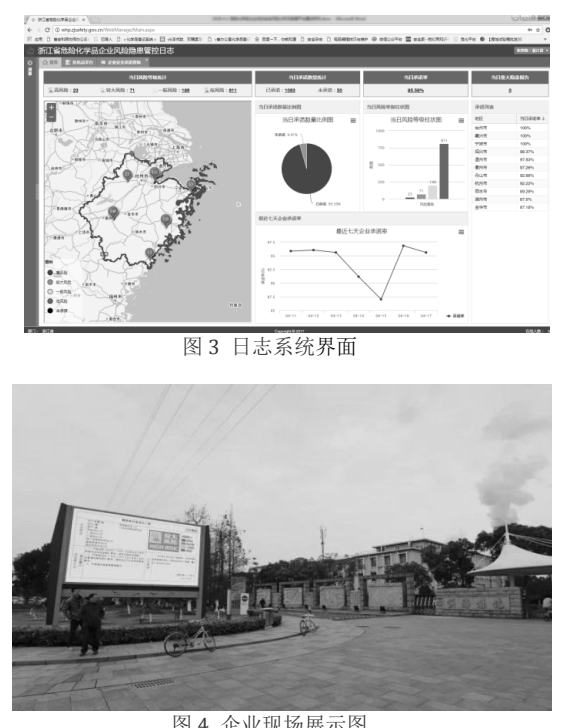

图 4 企业现场展示图

通过风险隐患管控日志系统和动态风险模型 的应用, 强化了企业对人的不安全行为和环境的不 安全条件的风险研判, 促使企业内部建立了自上而 下的风险辨识和防控制度，通过常态化的风险研判、 风险评估、风险分级和风险控制, 落实了企业生产、 经营和管理全链条安全风险管控责任, 为浙江省加 强和保障化工行业的安全生产打下良好的基础。

\section{5 总结与展望}

安全风险分级管控和隐患排查治理双重预防 性工作机制是当前有效防范和遏制重特大事故的 重要举措。本文通过对浙江省危化行业的事故统计 分析, 初步建立了危化品生产企业的动态风险分级 模型。借助浙江省危化品综合整治方案实施, 对危 险化学品生产企业进行了风险隐患分级, 借助多层 级危化品企业安全风险摸排、危化品风险数据库建 立、风险模型实施和安全风险日志管理, 打造了全 员、全过程、全天候风险管控链, 建立了良好的数 据基础, 确立了用数据说话、用数据决策、用数据 管理、用数据创新的理念和监管机制[11]。

本文创建的危化品生产企业安全风险分级模 型, 特别是动态风险所用到的分级标准、评价方法 并非最佳, 如人员素质动态性、自动化水平评价、 企业设备可靠性、作业数量与风险关联性等指标还 有很大的提升空间, 需要更进一步分析、辨识企业 的危险有害因素, 以便选取更合适的分级内容和方 法。 


\section{Acknowledgements}

This study was supported by Science and technology project of Zhejiang Province (No.2018C03035)

\section{致谢}

本研究得到了浙江省科技计划项目 (2018C03035) 的资助。

\section{参考文献}

[1] 王景. 我国危化品企业社会责任的伦理研究. 湖南工业大学, 2017 .

[2] 安全生产综合统计信息直报系统. 浙江省安全 生产监督管理局

[3] 刘蓉. 化工生产企业事故分析与预测研究.中 北大学, 2015 .

[4] 刘海峰. 基于风险管理理论的政府安全生产 监管模式研究.中国地质大学 (北京),2014.

[5] 江丽.浅析我国危化品管理风险信息公开机制. 时代经贸,2017(31):75-76.
[6] 孙斌,田水承, 常心坦. 事故风险评价与风险管 理模式研究.中国矿业,2003(01):73-75.

[7] 化工 (危险化学品) 企业保障生产安全十条规 定, 国家安全生产监督管理总局 64 号令, 2013.

[8] Roberto B, Efficient Applications of Risk Analysis in the Chemical Industry and Emergency Response,Journal of Risk Analysis and Crisis Response, 2011, 1(2): 92-101.

[9] Zhu J M, Fang $\mathrm{Y} \mathrm{Z}$, Jiang $\mathrm{C} \mathrm{H}$, $\mathrm{Hu} \mathrm{S}$ Y. Research on remote monitoring and control of big data platform based on internet of things. Proceeding of the 7th annual meeting of risk analysis council of china association for disaster prevention(November 4-6, 2016, Changsha, China), pp.870-870.

[10] 朱建炎, 汪圣华,张金峰. 基于物联网的安全生 产隐患实时监控服务平台的构建. 浙江工业 大学.安全生产应急管理与安全信息化的实践 研究-2015 浙江·第四届安全科学与工程技术 研讨会论文集.浙江工业大学,2015:5.

[11] 黄通晓. 政府危化品监管的信息孤岛问题研 究.华东师范大学, 2017 . 